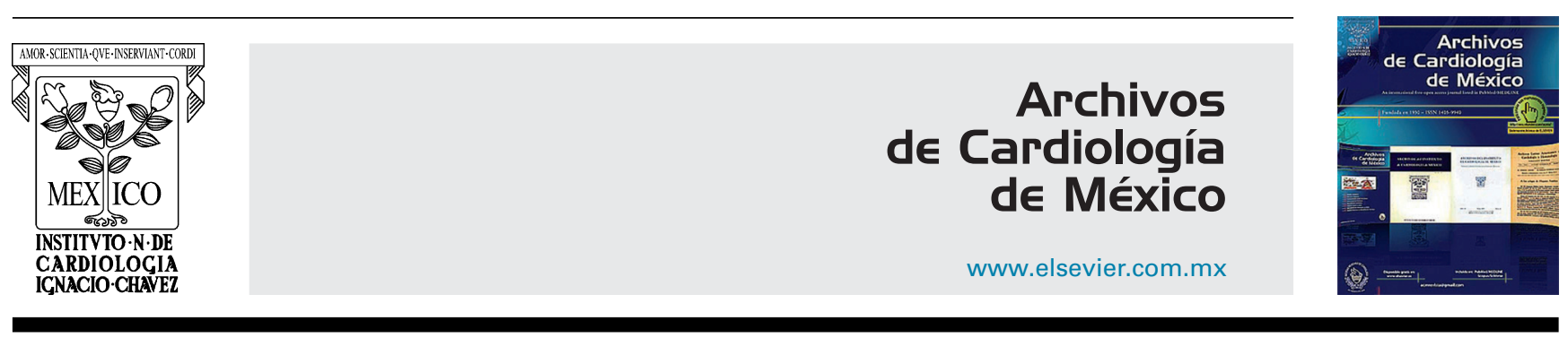

CARTAS CIENTÍFICAS

\section{Endocarditis de Libman-Sacks en válvula mitral nativa}

\section{Native mitral valve Libman-Sacks endocarditis \\ Introducción}

La endocarditis de Libmam-Sacks (ELS) es una de las manifestaciones cardiacas del lupus eritematoso sistémico (LES), más comúnmente cuando se asocia a síndrome antifosfolípido $(\mathrm{SAF})^{1,2}$. Estas vegetaciones son estériles, con crecimiento anormal alrededor de las válvulas, y con patogénesis trombótica e inflamatoria mediada por mecanismos autoinmunes $^{3}$. Aparecen predominantemente en las válvulas del lado izquierdo del corazón, se detectan por medio de ecocardiografía en aproximadamente $11 \%$ de los pacientes con LES y se ha reportado en el $30-50 \%$ de autopsias en estos pacientes ${ }^{4,5}$. Por lo general la ELS no produce síntomas en quienes la portan, sin embargo, puede llevar a una morbilidad significativa debido a eventos tromboembólicos (ictus, accidente isquémico transitorio, isquemia intestinal o embolismo arterial periférico), sobreinfección bacteriana de estas vegetaciones y lesiones valvulares severas que requieran cirugía ${ }^{6}$.

\section{Caso clínico}

Paciente mujer de 28 años de edad, quien presentó 3 semanas antes de su ingreso, disnea a moderados esfuerzos que progresó a ortopnea. Una semana antes de su ingreso presentó epigastralgia, la cual no se calmó a pesar de diversos tratamientos indicados en centros de salud de su localidad, por lo cual fue trasladada al Servicio de Emergencias del Hospital Universitario de Los Andes. Tiene como antecedentes LES y SAF diagnosticado a los 15 años de edad, sin tratamiento en el momento de la evaluación, por abandono voluntario de la paciente. Presentaba una herida traumática en la pierna izquierda, la cual ameritó injerto de piel en el año 2005 y que, al momento de su ingreso, se encontró sobreinfectada. El servicio tratante solicitó valoración por cardiología, y se realizó ecocardiograma transtorácico (fig. 1), en el cual se observó engrosamiento de las porciones distales de ambas valvas de la válvula mitral, que generaba imagen de bordes irregulares y condicionaba a insuficiencia leve. Se solicitó hemocultivo, el cual resultó negativo hasta 7 días después de la incubación, y se realizó ecocardiograma transesofágico (fig. 2), en el cual se observaron imágenes ecogénicas, fijas, de bordes irregulares, adosadas a la superficie auricular de la valva anterior y posterior de la válvula mitral, de $14 \times 9 \mathrm{~mm}$ y $8 \times 5 \mathrm{~mm}$ respectivamente. Se solicitó un nuevo hemocultivo, el cual resultó nuevamente negativo. Además de ello la proteína $c$ reactiva y la velocidad de sedimentación globular se encontraban dentro de límites normales, por lo cual no se inició antibioticoterapia. La paciente fue valorada por el servicio de reumatología, quienes determinaron que se encontraba con actividad lúpica e indicaron tratamiento inmunosupresor. Ante todos estos hallazgos clínicos y paraclínicos determinamos que las vegetaciones observadas en la paciente no eran debido a infección bacteriana, sino que concordaban con el diagnóstico de ELS.

\section{Discusión}

En el LES se puede observar pericarditis, miocarditis y afectación valvular dada por engrosamiento valvular, insuficiencia o estenosis valvular y ELS. Las vegetaciones valvulares debidas a ELS están presentes en uno de cada 10 de estos pacientes ${ }^{2,7}$.

La patogénesis de la ELS no está completamente clara. Se plantea que inicialmente actúan mecanismos inmunológicos dados por la presencia de inmunoglobulinas y complemento en las válvulas afectadas. Las vegetaciones verrucosas se asocian a un estadio final en el cual fluctúan depósitos de tejido fibroso y en algunos casos calcificación focal ${ }^{6}$. Estudios histopatológicos revelan que hay inflamación con proliferación celular, degeneración, infiltrados mononucleares y depósitos de fibrina ${ }^{8}$.

El diagnóstico puede ser difícil, ya que durante su evolución es asintomática. En la paciente atribuimos el diagnóstico de ELS debido a los antecedentes del LES y SAF, además no tenía tratamiento inmunosupresor por no adherencia al mismo.

En el ecocardiograma se pueden observar masas valvulares o vegetaciones, y engrosamiento valvular. Las masas pueden variar de forma y tamaño, generalmente más de $2 \mathrm{~mm}$ de diámetro, con bordes que usualmente son irregulares, adheridas firmemente a la superficie valvular auricular o ventricular, sin exhibir movimientos independientes. Las válvulas que se afectan con mayor frecuencia son las del lado izquierdo. Cuando la válvula mitral se encuentra afectada, las vegetaciones se pueden extender al aparato subvalvular y al endocardio adyacente a la valva ${ }^{6}$. En este caso las masas sobrepasaban los $5 \mathrm{~mm}$, y se encontraban sésiles en la superficie auricular de la válvula mitral, sin extenderse al aparato subvalvular, y como se vio en el ecocardiograma transesofágico había insuficiencia mitral leve. 


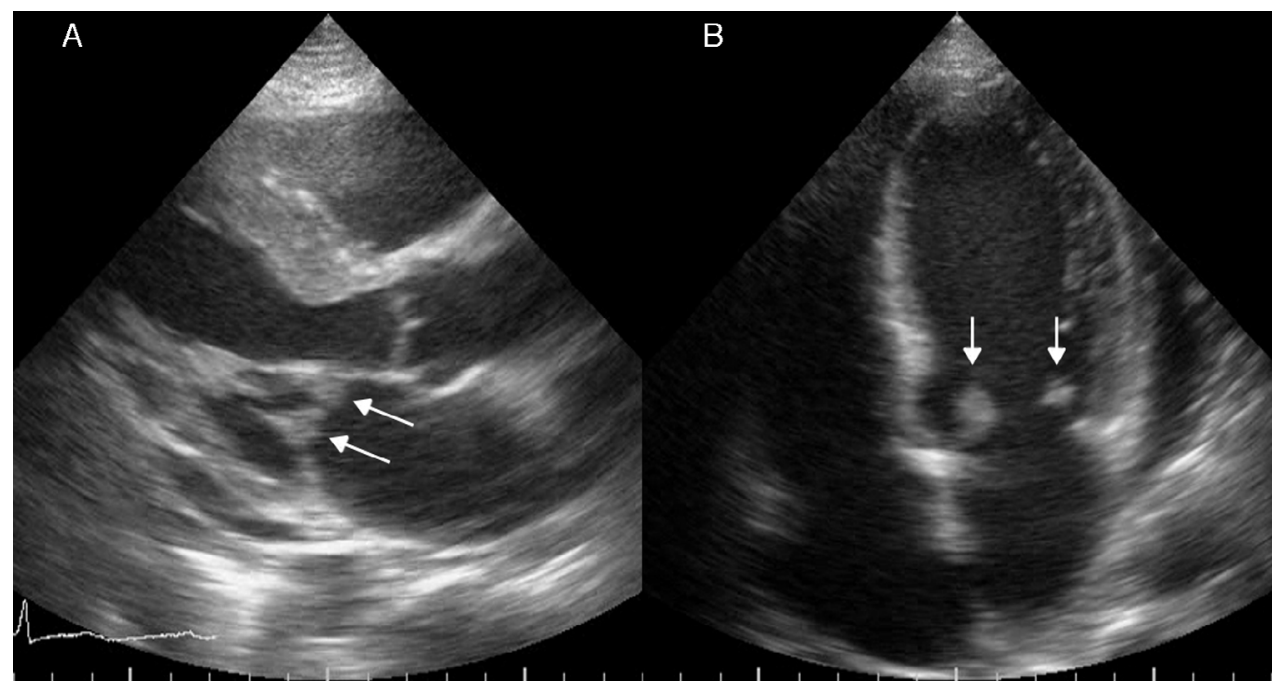

Figura 1 Ecocardiograma transtorácico. A. Vista en eje paraesternal largo. B. Vista de 4 cámaras. En ambas vistas se observa imagen de bordes irregulares, que produce engrosamiento de ambas valvas de la válvula mitral en sus porciones distales (flechas).

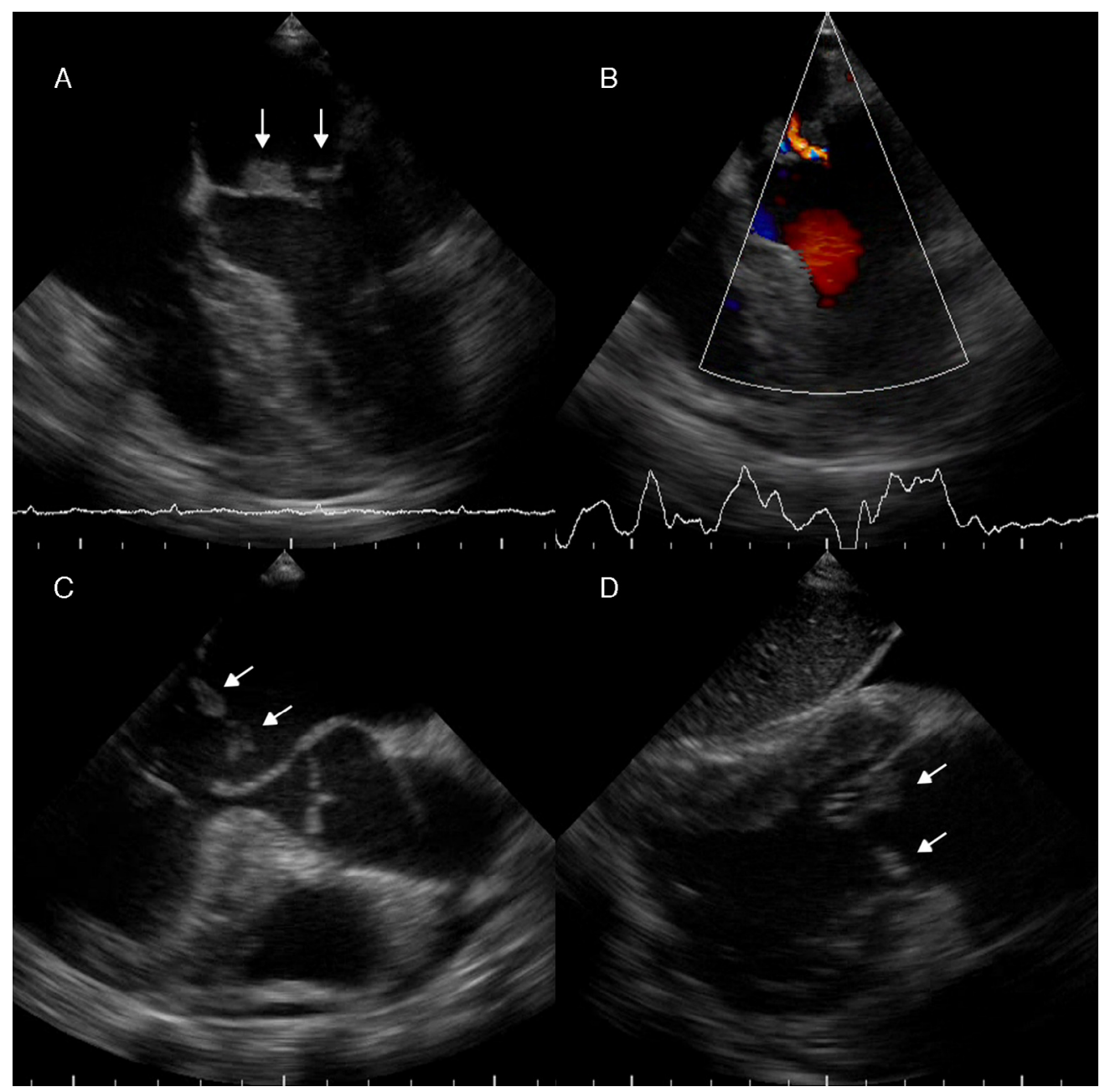

Figura 2 Ecocardiograma transesofágico. A y B. Vista medio esofágica de 4 cámaras (modificada), en las que se observan imágenes ecogénicas en la superficie auricular de ambas valvas de la válvula mitral, de gran tamaño, de bordes irregulares, sésiles, en festones A2 y P2 (flechas), que con doppler color permite observar insuficiencia valvular leve. C. Vista medio esofágica de eje largo de la válvula aórtica (modificada), donde se observan ambas vegetaciones adosadas a la superficie auricular de las valvas de la válvula mitral (flechas). D. Vista transgástrica de 2 cámaras. Se observan vegetaciones en la superficie auricular de las valvas de la válvula mitral (flechas). 
El tratamiento inmunosupresor, particularmente con corticosteroides, es la base del tratamiento del LES para controlar su actividad, pero a pesar que estos fármacos facilitan la disminución gradual de las lesiones, disminuyendo la inflamación, también promueven la fibrosis y cicatrización resultando en un daño valvular adicional. Cuando un paciente posee ELS en estadio activo se recomienda corticosteroides (prednisona $1 \mathrm{mg} / \mathrm{kg} / \mathrm{día})^{6}$. El tratamiento quirúrgico de la enfermedad valvular por LES tiene las mismas indicaciones que el tratamiento de las valvulopatías por otras causas ${ }^{1}$. Hay controversias entre el uso de reparación o reemplazo valvular. El reemplazo valvular tiene tasas más bajas de recurrencia de la enfermedad, comparada con la reparación valvular, y puede ser preferida en los casos más severos y sintomáticos ${ }^{8}$. La anticoagulación crónica está indicada como prevención secundaria en pacientes con enfermedad valvular con anticuerpos antifosfolípidos que ya han presentado un evento embólico ${ }^{1}$. En la paciente, a pesar de que una de las lesiones midió más de $10 \mathrm{~mm}$, se decidió realizar un tratamiento conservador inicialmente, en el que se reinició la terapia para LES, anticoagulación con warfarina y posteriormente revaloración con ecocardiograma transtorácico para evaluar la evolución del tamaño de las vegetaciones y la función de la válvula.

Los diagnósticos diferenciales de la ELS comprenden la enfermedad valvular reumática, la endocarditis infecciosa y la endocarditis trombótica no bacteriana (marántica). En la endocarditis marántica las vegetaciones usualmente se hallan adheridas a la línea de cierre de la válvula.

\section{Bibliografía}

1. Saldarriaga C, Múnera AG, Duque M. Endocarditis de LibmanSacks. Rev Colomb Cardiol. 2015;22:144-8.

2. Shroff $H$, Benenstein R, Freedberg $R$, et al. Mitral valve Libman-Sacks endocarditis visualized by real time threedimensional transesophageal echocardiography. Echocardiography. 2012;29:E100-1.
3. Roldan CA, Tolstrup K, Macias L, et al. Libman-Sacks Endocarditis: detection, characterization, and clinical correlates by three-dimensional transesophageal echocardiography. J Am Soc Echocardiogr. 2015;28:770-9.

4. Marques RA, Gonçalves-Freitas CS, Ceccon R, et al. Libman-Sacks endocarditis, antiphospholipid antibodies and arterial thrombosis in systemic lupus erythematosus: Case report. Bras J Rheumatol. 2010;50:716-22.

5. Moyssakis I, Tektonidou MG, Vasilliou VA, et al. LibmanSacks endocarditis in systemic lupus erythematosus: Prevalence, associations, and evolution. Am J Med. 2007;120: 636-42.

6. Ferreira E, Bettencourt PM, Moura LM. Valvular lesions in patients with systemic lupus erythematosus and antiphospholipid syndrome: An old disease but a persistent challenge. Rev Port Cardiol. 2012;31:295-9.

7. Salvador MTE, Navarra SV. Infective versus Libman Sacks endocarditis in systemic lupus erythematosus. Rheumatol Curr Res. 2013;:S16:001-3.

8. Akhlaq A, Ali TA, Fatimi SH. Mitral valve replacement in systemic lupus erythematosus associated Libman-Sacks endocarditis. J Saudi Heart Assoc. 2016;28:124-6.

Carlos Eduardo Vergara-Uzcategui* y José Hipólito Donís

Servicio de Cardiología, Instituto de Investigaciones Cardiovasculares, Hospital Universitario de Los Andes, Universidad de Los Andes, Mérida, Venezuela

* Autor para correspondencia. Avenida 16 de Septiembre, Hospital Universitario de Los Andes. Nivel Emergencia. Mérida, Venezuela. Código postal 05101.

Correo electrónico: carting1@gmail.com

(C.E. Vergara-Uzcategui).

http://dx.doi.org/10.1016/j.acmx.2017.04.001

1405-9940/

(c) 2017 Instituto Nacional de Cardiología Ignacio Chávez. Publicado por Masson Doyma México S.A. Este es un artículo Open Access bajo la licencia CC BY-NC-ND (http://creativecommons.org/ licenses/by-nc-nd/4.0/).

\section{¿Cuándo una afectación valvular cardíaca puede orientar al diagnóstico de un tumor maligno?}

\section{When a cardiac valvular affectation can guide to the diagnosis of a malignant tumor?}

\section{Introducción}

El síndrome carcinoide (SC) se genera por un exceso de secreción hormonal (habitualmente serotonina), manifestándose fundamentalmente como rubefacción cutánea, diarrea, broncoespasmo y cardiopatía valvular. El SC es una causa rara de enfermedad valvular adquirida. Sin embargo, más de la mitad de los pacientes que padecen de este síndrome tienen daño cardíaco, afectando generalmente a varias válvulas cardíacas.
A continuación, presentamos un caso de enfermedad polivalvular que condujo al diagnóstico de SC.

\section{Caso clínico}

Se trata de una mujer de 48 años sin hábitos tóxicos y con antecedentes personales de hipertensión arterial, hipotiroidismo, trastorno ansioso-depresivo y diarrea crónica con colonoscopia realizada en el mes previo sin hallazgos reseñables. La paciente consultó en nuestra institución por disnea de esfuerzo progresiva, hiporexia y pérdida de peso de $15 \mathrm{~kg}$. En la exploración física destacaban telangiectasias malares, signos de congestión derecha y soplo sistólico ॥/vı. Se realizó un ecocardiograma transtorácico donde se observó dilatación del ventrículo derecho, aurícula izquierda dilatada de forma moderada y datos de afectación inflamatoria en las válvulas cardíacas: a) tricúspide engrosada sin calcificación e inmóvil en posición de apertura, generando una insuficiencia tricúspide masiva (figs. 1 A y B); 